\title{
ENTRE A CRÍTICA E O CIENTIFICISMO ${ }^{1}$
}

\section{Mário Fernando BOLOGNESI ${ }^{2}$}

O intuito principal das primeiras Jornadas de Filosofia era criar um ambiente de discussão interdisciplinar, em torno das Ciências Humanas, com vistas a criar condições para que se estruturasse um curso de pós-graduação em Filosofia, na UNESP. No início, o projeto caminhava sob o jugo dos Institutos Isolados da Universidade de São Paulo. Com o nascimento da Universidade Estadual Paulista e com o remanejamento de vários cursos, processo levado a cabo pelo então reitor (em alguns casos sem a necessária dose de bom senso e contra a vontade de professores e alunos), o Departamento de Filosofia viu-se diante da necessidade de reestruturar-se, tendo em vista a sua nova localização. Dessa reestruturação nasceu o atual currículo, fortemente marcado pela imperiosa necessidade de juntar-se às Ciências Sociais, do Campus de Marília.

As Jornadas prosseguiram e o Departamento, de certa forma, abandonou o projeto inicial de constituição de uma pós-graduação em Filosofia e Teoria das Ciências Humanas. As razões desse abandono foram diversas e não se trata, aqui, de recuperá-las. Essa é uma tarefa que não se adequa a este momento.

Passados os anos, contudo, a discussão de uma pós em Filosofia, na UNESP, voltou à tona, com um Departamento muito diverso em seus corpos docente e discente. Hoje, parece que a tarefa tornou-se imperiosa. Entretanto, deve estar voltada à realidade teórica e profissional dos componentes do Departamento, e é nesse sentido que as discussões em torno da pós-graduação têm-se dirigido.

Nesse retorno do desejo e da necessidade de uma pós-graduação, os objetivos, pode-se dizer, desviaram-se do tema e do objeto iniciais das Jornadas, quais sejam

\footnotetext{
1 Texto apresentado na abertura da XVIII Jornada de Filosofia e Teoria das Ciências Humanas, de 19 a 21 de outubro de 1994, na Faculdade de Filosofia e Ciências - UNESP, Campus de Marilia.

2 Professor do Departamento de Filosofia, da Faculdade de Filosofia e Ciências - UNESP - 17525-900 - Marília - SP - Brasil.
} 
Filosofia e Teoria das Ciências Humanas. Porém, antes mesmo que a própria Jornada seja revista - se é que o será! -, a Comissão Organizadora preparou, para este ano, a discussão de alguns temas fundamentais para a compreensão de certos aspectos da vida contemporânea, à luz de pensadores que buscaram nos autores clássicos do marxismo, e na filosofia alemã, em geral, o entendimento das formas e modos de ação social e do pensamento na realidade do mundo burocrático e autoritário, demarcado pelo nazismo e stalinismo. A intenção, portanto, é rever as investigações acerca das relações da estética com a política, da filosofia com a revolução e de como esses temas e procedimentos foram introduzidos e se desenvolveram no Brasil.

A XVIII Jornada de Filosofia e Teoria das Ciências Humanas, que hoje se inicia, tem como tema o Marxismo ocidental. Professores de diversas instituições de ensino e pesquisa do país estarão reunidos, nesses três dias, para tratar do assunto proposto, cuja base teórica nos remete a Sartre, Adorno, Benjamin, Horkheimer, Marcuse e outros.

Do ponto de vista filosófico, esta Jornada certamente se prestará a rever os modos sob os quais está se dando, na atualidade, a coisificação do homem, em um mundo que se materializou por completo.

Expressão mais acabada dessa materialização é a tradução econômica dos principais motivos da existência. Mercadoria e dinheiro passaram a ser os elementos básicos, uma espécie de café da manhã que orienta os afazeres e preocupações do cotidiano. As relações entre as pessoas são relações entre coisas. Vivemos em um mundo em que os mais íntimos desejos são coisificados.

Além de manifestar-se através das coisas, a existência tornou-se, ela própria, um produto, ou seja, adquiriu grandeza de valor. O valor de uso é a amplitude de sua necessidade; o de troca se mede pelas formas sociais de sua manifestação.

Indignados com isso, os românticos atuais (seguindo os do passado) procuram expor a dominação da troca sobre o uso, como se este fosse próprio do homem (e nesse sentido natural) e aquela, a troca, da sociedade (isto é, cultural). Haveria, assim, o aniquilamento do humano em nome do social, tema, aliás, dos mais profícuos para o pensamento político e para a prática artística e cultural do Ocidente, porque envolve a dialetização do indivíduo com o Estado, do sujeito com o coletivo.

Admitindo-se que a essência de algo manifesta-se através de sua aparência, e que esta contém a primeira, vive-se de acordo com as formas e práticas próprias aos tempos atuais. Essas formas e práticas, que compõem os rituais da contemporaneidade, cristalizam-se nas diversas mercadorias e produtos. Resta, no entanto, uma séria questão: os homens se coisificaram, ou as coisas se humanizaram?

No plano da consciência e do pensamento é como se estivesse ocorrendo um sucumbir da lucidez, uma espécie de institucionalização do mercado das consciências, cuja finalidade é transformar as exceções em regras. Viver, nos tempos e no Brasil atuais, é um desafio contra a venda da consciência e da ação. Há uma visível dicotomia entre os modos de ação e a concordância com essas ações. Pensa-se de 
uma forma e age-se de outra. Ação e consciência sujeitaram-se ao mercado da persuasão das idéias, da cultura, das classes, da política e da ética.

Nesse mercado compram-se cabeças, desviam-se vontades e desejos, em troca de um bem-estar prometido, quase sempre terminando em mera subsistência. Troca-se uma atitude vazia por silêncio conivente. Às vezes, vende-se um pensamento contundente ao preço do isolamento bem acomodado. Outras, sucumbe-se aos valores degradantes das idéias bem comportadas.

No mercado da persuasão, termina-se por curvar-se diante da opressão. Se a necessidade de obediência cedeu às contingências, parece que chegou a vez de o pensamento tomar o mesmo caminho. O conformismo das idéias e das ações só reitera o modo burocrático e policialesco (ainda que disfarçado) que o dia-a-dia tomou. A subversão do pensamento, que, de certa forma, alimenta a transformação social, que propulsiona ideais ainda não alcançados, deixou de existir, em nome de uma mesmice reiterativa, dando os contornos e os limites de uma existência quase bestializada.

Abundância dos bens materiais de consumo; acesso crescente à cultura e à informação; ampliação dos índices de alfabetização; sofisticação intermitente no trabalho; conquistas tecnológicas aplicadas ao dia-a-dia no lar; facilidades de locomoção etc. - eis algumas características da vida contemporânea. Paradoxalmente, porém, os ganhos materiais têm sido acompanhados de uma gradativa perda da liberdade, de um vazio existencial, enfim, do esvaziamento do livre arbítrio, com prejuízos notáveis à autonomia do sujeito.

Quanto maior a sensação de felicidade nos bens de consumo, maior a rendição à sociedade de massas, que aniquila com a noção de cidadão para fazer prevalecer a de consumidor, necessidade imperiosa do progresso técnico e industrial, baseado no individualismo do self made man. A sofisticação da vida cotidiana tem como contrapartida a perda da identidade, da felicidade e da liberdade.

Os assim chamados atributos essenciais do sujeito estão vilipendiados, bem como esvaziado o conceito de luta de classes, matriz primordial do pensamento marxista em sua análise do capitalismo. O modo contemporâneo de existência rege-se, exclusivamente, pelo poder aquisitivo, restrito, portanto, a uma parcela mínima da população. O Terceiro Mundo recebe o rótulo e o papel de massa, em um modelo social tecnocrático e objetual, mesmo que a imensa maioria não tenha condição de participar da sociedade de consumo. É de notar, todavia, como essa maioria se vê como massa participante. A fantasia se satisfaz com o conforto alheio, motivada por uma educação tecnicista e pelos veículos de comunicação que semeiam o bem-estar social, mesmo que a distância. A felicidade restringe-se às imagens (visuais e mentais) das lojas da rua principal, dos shoppings, da moda, dos veículos de comunicação etc.

Perdeu-se a dimensão do todo. Não há mais tempo para refletir acerca da singeleza dos atos e pensamentos, que caminham na contramão da oficialidade, postura quase insignificante, não fosse o valor que assume diante de um cotidiano 
conturbado. Cada vez mais escassos, a ação e o pensar, que não se traduzem em mercadorias, são vistos como extemporâneos, arcaicos, participantes de um mundo que há muito se foi. Anulou-se o direito de revolta e a utopia passa ao largo: resquício de um tempo perdido. Já não se tem a capacidade de sonhar e lutar por ideais. $O$ mundo ideal se resume no aumento de renda, com vistas ao maior consumo. Mais do que nunca este velho assunto se faz presente e esta é uma das fortes razões para se rediscutir o marxismo, tal como proposto nesta Jornada.

No plano da cultura, das artes e da estética, o ambiente é igualmente desolador. Nas décadas passadas, o ato de ver um filme, ler um romance, assistir a uma representação teatral ou contemplar uma obra plástica era sinônimo de colocar-se diante de um universo propiciador de diversão, mas também de reflexão.

Afora as exceções de sempre, as artes e a prática cultural trabalhavam no limiar de um discurso anterior, teórico e político, sustentador do modo de se fazer a obra. Por certo, também havia aquele burburinho falsificador de valores, que cultuava uma determinada obra, ou artista, pelo simples jogo do convívio social, quase sempre demarcador de fronteiras e, portanto, de limites de classe.

Hoje, contudo, o processo acelerador da democratização da cultura e da comunicação trouxe a falência daquele substrato teórico e político, que sempre sustentou os grandes momentos da cultura ocidental. Ou, para ser mais preciso, alterou-se a relação da arte com a política, deixando de lado a forma e o conteúdo da obra para alojar-se nos meandros estruturais da produção e reprodução da cultura.

O que teria acontecido com nossa sensibilidade? Dominada pelo universo neoliberal e pelos palpites difusos e confusos da pós-modernidade, a sensibilidade tem-se conformado ao papel de assistente e receptora de valores artísticos, morais, sociais e políticos que pululam nos diversos meios de difusão da cultura e da informação. Hoje, um novo modo de exercício do poder se efetiva, com maior eficácia, a distância, através do domínio da produção simbólica.

A alteração desse panorama ocorreu, na história recente, a partir da década de 1960, um período, dentre outras coisas, marcado pelas lutas de libertação nacional em vários países do Terceiro Mundo. O intervencionismo direto das grandes potências, além de questionado, mostrou-se, na própria lógica do capital, inadequado politicamente. É conveniente ressaltar que o processo de descolonização dos anos 60 foi movido pelo intento primeiromundista de um neocolonialismo. Se, à primeira vista, pode-se ver os diversos movimentos de libertação nacional, ou mesmo o pulular dos movimentos das minorias, como um momento de triunfo sobre o imperialismo, pode-se igualmente encarar como um processo de expansão qualitativa do capitalismo, com a implantação de um arsenal tecnológico bastante inovador e com novos meios de produção. $\mathrm{O}$ antigo imperialismo saía de cena para dar lugar a uma nova forma de dominação.

Dentre outros, assistiu-se, naquele período, ao avanço e crescimento da indústria da cultura e da comunicação, criando padrões ágeis e com certo grau de eficiência 
junto ao imaginário coletivo. Em pouco tempo essa indústria viria a ser plenamente adequada aos exercícios do poder.

Esse ramo da indústria mostrou-se capaz não apenas de estender o acesso à cultura, como a produzir e reproduzir símbolos e, portanto, a conformar o universo das representações e valores mentais. É certo, também, que o fator econômico desempenhou papel importante, pois o capital encontrou na cultura uma fonte de exploração. Contudo, naquele momento, o dado fundamental é que o capitalismo tinha encontrado um modo de continuar o seu projeto de sociedade e civilização, sem intervir diretamente nos problemas nacionais dos países dependentes. As experiências do Vietnã e da Argélia, para citar apenas duas, tinham sido demasiado trágicas para o Primeiro Mundo.

Hoje, diante deste novo modo de exercício do poder, essencialmente simbólico, há um nítido conformismo com os valores postos e repostos pelos veículos de manifestação da cultura e da comunicação e nossa sensibilidade retrai-se diante de modelos culturais consagrados pelo projeto industrial.

Alteraram-se os tempos, as obras, os valores, mas a arte, a cultura, a linguagem e até mesmo a sensibilidade atrelaram-se ainda mais à política. Desta feita, como forma quase que privilegiada de dominação social, a distância.

No plano da investigação das idéias assistiu-se a uma substituição gradual dos grandes sistemas filosóficos e políticos, particularmente o existencialismo sartreano e o marxismo, predominantes nos meios acadêmicos (porém não hegemônicos), pelo chamado estruturalismo. O movimento parecia extremamente claro: a primazia da linguagem e do simbólico deveria sobrepor-se à tentativa filosófica de reflexão acerca do mundo e da existência. Em última instância, houve um abandono das investigações críticas e filosóficas para fazer prevalecer um cientificismo do qual se mostravam carentes todas as ciências humanas. Do ponto de vista do método e do procedimento científicos, o estruturalismo estava muito mais bem equipado. Este caminho viria a implicar, mais tarde, o descaso completo para com o pensamento crítico (em seu questionamento das relações de poder e dominação, que se estendia à reflexão acerca da existência, do mundo e das coisas), bem ao gosto da pós-modernidade. A pulverização dos conceitos e o desmantelamento teórico dos arcabouços filosóficos, nos quais se inclui o marxismo, foram a contrapartida do conhecimento tecnicista, que tem predominado desde então, a despeito ainda da queda do modismo estruturalista. Restou, contudo, a postura da especialidade, do avanço sistemático do singular em oposição à tentativa de compreensão crítica de uma totalidade, atributo histórico da Filosofia. O caminho do cientificismo predominante acabou por sepultar de vez 0 sujeito filosófico e a sua tarefa. A partir de então, a Filosofia teria de dar suporte teórico à pesquisa das ciências, voltada, com maior ou menor intensidade, ao aprimoramento do mundo tecnológico, tendo como crença suprema a autonomia e independência do conhecimento. Vale dizer: sua tarefa deixou de ser a reflexão e a crítica para transformar-se em produtora de sentidos para o trabalho da ciência. A própria Filosofia 
se tecnicizou, ou melhor, materializou-se, não no sentido clássico do materialismo, mas na função quase que primordial de dar sustentáculo teórico e material à linguagem e ao universo simbólico - em última instância, prover de sentido o trabalho científico.

Assim, senhoras e senhores, pretende-se, com esta Jornada, além de discutir os temas específicos da estética e da política, à luz do marxismo ocidental, colocar em foco, ainda que indiretamente, o próprio papel da Filosofia. Essa tarefa faz-se necessária em um momento em que, internamente, pensa-se na reestruturação curricular e na instalação de uma pós-graduação. No plano mais geral do conhecimento, em um mundo entregue ao mercado, tanto das coisas como das consciências, ela também se mostra pertinente, ainda que seja para repor uma reflexão da qual somos cotidianamente distanciados, em nome de uma especialidade que nada mais faz do que reiterar a pulverização do pensamento, passo primordial para um discurso positivo. Nesse itinerário intermitente de supremacia do objeto e do objetivismo, restam quase sempre esquecidos os propósitos ulteriores da crítica filosófica, sintetizados na liberdade ou na autonomia do sujeito, que para o marxismo deve redundar na compreensão da luta de classes e no aniquilamento da dominação. Se hoje a dialética entre o sujeito e o objeto apresenta uma soberania do segundo elemento sobre o primeiro, demarcador por certo do grau de reificação alcançado, é chegado o momento, uma vez mais, de propor, no nível da reflexão ao menos, o papel da utopia no convívio social e no trabalho crítico da Filosofia. Ou devemos abandoná-la de vez e deixar que a razão sucumba definitivamente ao mundo objetual do trabalho? É possível que não se alcance resposta convincente. Contudo, vale o intento de recolocar a temática da crítica, que em nada corrobora o universo do consumo, tanto material quanto, principalmente, simbólico.

Esses são alguns temas que esta Jornada certamente tocará. Antigas questões que cada vez mais são pertinentes, porque confluem para a problemática política da existência, do consumo, da anulação do sujeito, da derrocada da revolução e da dominação de classe, travestidas ideologicamente em eficiência, especialidade e verdade para um mundo e uma consciência partidos, fragmentados, enfim, tecnicizados em seus fetiches.

BOLOGNESI, M. F. Between critique and scientism. Trans/Form/Ação (São Paulo), v.18, p.23-28, 1995. 